\title{
Preoperative squamous cell carcinoma antigen and albumin serum levels predict the survival of patients with stage T1- 3N0M0 esophageal squamous cell carcinoma: a retrospective observational study
}

Lei-Lei $\mathrm{Wu}^{\dagger} \mathbb{B}$, Xuan Liư ${ }^{\dagger}$, Wei Huang, Peng Lin, Hao Long, Lan-Jun Zhang and Guo-Wei Ma*

\begin{abstract}
Background: This study aimed to explore the significance of preoperative levels of squamous cell carcinoma antigen (SCC-Ag) and albumin on the cancer-specific survival (CSS) of patients with stage T1-3NOM0 in esophageal squamous cell cancer (ESCC).

Methods: The data of 308 patients who underwent esophagectomy between 1996 and 2011 were analyzed. SCC$\mathrm{Ag}$ and albumin levels were measure 1 week before surgery. The optimal cutoff levels of SCC-Ag and albumin were determined using the X-Tile software, which were $1.0 \mu \mathrm{g} / \mathrm{L}$ and $39.8 \mathrm{~g} / \mathrm{L}$, respectively. The associations between SCC-Ag and albumin levels and clinicopathological characteristics were assessed using the $x^{2}$ test, Student's t-test and Fisher's exact test. Cox univariable and multivariable analyses were computed to identify SCC-Ag and albumin levels as independent prognostic factors related to the CSS of patients with ESCC. We used the Kaplan-Meier survival curve to determine the significance of SCC-Ag and albumin level on ESCC in the long-term follow-up.

Results: The 5-year CSS rate for the entire cohort was 65.0\%. There was a significant difference in CSS between the low and high SCC-Ag level groups (hazard ratio [HR], 1.828, 95\% confidence interval [Cl], 1.203-2.778; $P=0.005$ ). Patients with ESCC with low albumin level had a worse CSS than those with high albumin level $(\mathrm{HR}, 0.540 ; 95 \% \mathrm{Cl}$, 0.348-0.838; $P=0.006$ ). Patients with both high SCC-Ag and low albumin levels had worse 5 -year CSS than patients with low SCC-Ag and high albumin levels $(P<0.05)$.
\end{abstract}

Conclusions: Preoperative serum SCC-Ag and albumin levels can predict survival in patients ESCC with stage T13NOMO. Patients with ESCC with high SCC-Ag and low albumin levels may have a poor survival outcome.

Keywords: Squamous cell carcinoma antigen, Albumin, Cancer-specific survival, Esophageal squamous cell cancer

\footnotetext{
* Correspondence: magw@sysucc.org.cn

'Lei-Lei Wu and Xuan Liu contributed equally to this work.

Department of Thoracic Surgery, Sun Yat-sen University Cancer Center, State Key Laboratory of Oncology in South China, Collaborative Innovation Center for Cancer Medicine, 651 Dongfeng East Road, Guangzhou 510060, P. R. China
}

(c) The Author(s). 2020 Open Access This article is licensed under a Creative Commons Attribution 4.0 International License, which permits use, sharing, adaptation, distribution and reproduction in any medium or format, as long as you give appropriate credit to the original author(s) and the source, provide a link to the Creative Commons licence, and indicate if changes were made. The images or other third party material in this article are included in the article's Creative Commons licence, unless indicated otherwise in a credit line to the material. If material is not included in the article's Creative Commons licence and your intended use is not permitted by statutory regulation or exceeds the permitted use, you will need to obtain permission directly from the copyright holder. To view a copy of this licence, visit http://creativecommons.org/licenses/by/4.0/. The Creative Commons Public Domain Dedication waiver (http://creativecommons.org/publicdomain/zero/1.0/) applies to the data made available in this article, unless otherwise stated in a credit line to the data. 


\section{Background}

Esophageal cancer ranks seventh among the most common cancers and sixth among malignancy-related mortality in men worldwide, especially in East Asia, of which more than half of the total cases globally are of Chinese origin [1, 2]. Contrary to Western countries, in China, esophageal squamous cell cancer (ESCC) accounts for > $90 \%$ of esophageal cancer cases [3, 4]. Despite the application of advanced surgical techniques, radiotherapy, and chemotherapy, the recurrence of ESCC remains inevitable and leads to poor prognosis [5].

Previous studies suggested that serum squamous cell carcinoma antigen (SCC-Ag) levels had likely an effect on prognosis of malignant tumor [6-9], such as oral squamous cell carcinoma [7, 10] and head and neck cancer $[11,12]$. Indeed, SCC-Ag is a widely used tumor marker in oncology. In addition, the findings of some studies revealed that serum albumin level might be related to the survival outcomes of patients with cancer, such as ovarian cancer [13] and endometrial cancer [14]. However, the significance of preoperative serum albumin levels is still unclear in the prognosis of patients with ESCC.

With regard to ESCC, existing literatures identified high SCC-Ag level as a predictor of poor prognosis $[6,15]$. Shimada et al. collected the medical records of 309 patients who underwent esophagectomy and analyzed the data of these patients with ESCC. They found that patients with high SCC-Ag level had worse survival $(P<0.05)$ [15]. In addition, Cao also validated the results of Shimada's study by analyzing the data of 379 patients with ESCC [6]. The two abovementioned studies included patients with metastasis of the lymph nodes (LNs).
This study aimed to investigate the exact value of SCC-Ag and albumin levels on the prognosis of patients with ESCC in stage T1-3N0M0. Patients with metastasis of the LNs were excluded because these patients would have better survival by receiving neoadjuvant therapy based on the results of Hong Yang's clinical trial [16].

\section{Methods}

\section{Patients and follow-up}

This retrospective study was approved by the ethics committee of Sun Yat-sen University Cancer Center (SYSUCC; Approval No. YB2016-070). Eligible cases, screened from the database of the Department of Thoracic Surgery in the SYSUCC, were defined as patients with ESCC histopathologically diagnosed as stage T13N0M0 after esophagectomy between 1996 and 2011. Patients with the following conditions were excluded: (1) neoadjuvant chemotherapy, neoadjuvant immunotherapy, or neoadjuvant radiotherapy; (2) cancers other than ESCC; (3) diagnosis of metastasis of LNs or other organs; (4) age > 75 years; (5) missing medical records; (6) primary tumor located at cervical esophagus; and (7) hepatitis, coronary heart disease, and other serious medical conditions. All patients were restaged based on the American Joint Committee on Cancer Staging Manual, eighth edition [17, 18]. Finally, a total of 308 patients were enrolled in our study (Fig. 1).

We recommend that patients visit the outpatient department for follow-up examination every 3 months for the first 2 years, then every 6 months for the next 3 years, and then every year thereafter. Follow-up examinations consisted of history taking, barium esophagography,

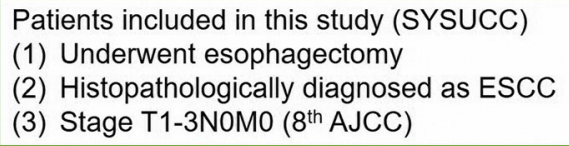

Patients excluded from this study:

(1) Received neoadjuvant chemotherapy, neoadjuvant immunotherapy, or neoadjuvant radiotherapy

(2) Cancers other than ESCC

(3) Diagnosed with metastasis of lymph nodes or other organs

(4) Medical records were missed

(5) Primary tumor located at cervical esophageal

(6) Hepatitis, coronary heart disease, and other serious medical conditions

(7) Over 75 years old 
physical examination, chest radiography, cervical ultrasonography, abdominal ultrasonography, and neckabdomen computed tomography (CT) scans. If necessary, patients underwent positron emission tomographyCT and/or endoscopy. The study's endpoint was cancerspecific survival (CSS), defined as the number of days from surgery to death caused by ESCC or the most recent follow-up visit. Data on CSS were collected from the follow-up records and verified by a special follow-up group. As of August 30, 2017, all patients in this study developed recurrence of LNs, previous surgical sites, and/or other organs. The median follow-up duration was 78.5 months.

\section{SCC-Ag and albumin levels and other data}

The serum SCC-Ag and albumin levels were routinely measured at the SYSUCC clinical laboratory 1 week preoperatively. The baseline data included sex, age, smoking history, alcohol consumption, primary tumor location, and number of LNs.

\section{Statistical methods}

All statistical analyses were performed using the SPSS software version 25.0 (IBM, SPSS, Inc., Chicago, IL, USA). All $P$-values were two sided, and a $P$-value $<0.05$ was considered statistically significant. The associations between SCC-Ag level, albumin level, and clinicopathological characteristics were assessed using the $x^{2}$ test, Student's t-test, and Fisher's exact test. In addition, we used linear regression and Pearson's correlation analysis to further explore the association between SCC-Ag and albumin levels. Standard deviation was used to evaluate the stability of continuous variables. Survival analyses were performed using life tables, Kaplan-Meier methods, and log-rank test. Cox regression and multivariate analyses were performed to identify whether SCC-Ag and albumin levels are independent prognostic factors in ESCC. In the previous studies, the X-Tile software (http://www.tissuearray.org/rimmlab v3.6.1) was used to determine the optimal cutoff value of some indicators $[19,20]$. We estimated the C-statistics for survival data established by X-Tile software, which was similar to time-dependent Receiver Operating Characteristic curve analysis [21]. Therefore, we used the X-Tile software to reach the optimal cutoff levels of SCC-Ag and albumin. The preoperative serum SCC-Ag and albumin levels were considered high when they were $>1.0 \mu \mathrm{g} / \mathrm{L}$ and $39.8 \mathrm{~g} / \mathrm{L}$, respectively. Given that the SCC-Ag and albumin levels were continuous variables, patients were classified into two groups according to their concentrations (SCC-Ag, low level $(0-1.0 \mu \mathrm{g} / \mathrm{L}, n=249)$, High level $(>1.0 \mu \mathrm{g} / \mathrm{L}, n=59)$; albumin, low level $(0-39.8 \mathrm{~g} / \mathrm{L}$, $n=49)$, high level (>39.8 g/L, $n=259)]$.

\section{Results}

\section{Basic clinical characteristics of patients}

Patients' characteristics are summarized in Table 1 . The study population consisted of 230 men (74.7\%) and 78 women $(25.3 \%)$ with a median age of 58.0 years (range, 33.0-75.0 years). The preoperative serum SCC-Ag level was low $(\leq 1.0 \mu \mathrm{g} / \mathrm{L})$ in $80.8 \%(n=249)$ and high $(>1.0 \mu \mathrm{g} /$ L) in $19.2 \%(n=59)$ of the study cohort. There were 49 (15.9\%) patients with low albumin level. Anastomotic leakage occurred in 28 patients during the perioperative period. The 1-, 3-, and 5-year CSS of all patients were 82.0, 69.0, and $65.0 \%$, respectively. The median survival time of this cohort was 77.5 months.

\section{Correlations between SCC-Ag and albumin levels and clinicopathological characteristics}

Table 1 shows the relationships between the SCC-Ag and albumin levels and various clinical and pathological features. We found that pathological $\mathrm{T}$ stage, age at diagnosis, length of tumor, and albumin level were likely to be associated with SCC-Ag level (all $P<0.05$ ). In addition, SCC-Ag level and age at diagnosis were related to preoperative albumin level (all $P<0.05$ ). We also found that the SCC-Ag level had a significant negative correlation with albumin level $(P=0.0234$, Fig. 2$)$ by Pearson's correlation analysis. However, the correlation was extremely weak $(r=-0.1291)$.

\section{Univariate and multivariate analyses}

Univariate and multivariate Cox regression analyses (Table 2) indicated that the five independent prognostic factors in patients with ESCC were alcohol consumption, pT staging, SCC-Ag level (adjusted hazard ratio $[\mathrm{HR}], 1.200 ; 95 \%$ confidence interval [CI], 1.083-1.330; $P=0.001$ ), LNs, and albumin level (adjusted HR, 0.945; 95\% CI, 0.896-0.997; $P=0.038$ ).

\section{Survival outcomes of patients}

Kaplan-Meier method demonstrated that a high serum SCC-Ag level $(P=0.005)$ or low serum albumin level $(P=0.006)$ were associated with low CSS rate in patients with ESCC (Fig. 3). Moreover, life tables revealed a difference in 1-, 3-, and 5-year CSS rates between the low and high SCC-Ag level groups (1-year CSS, $84.0 \%$ vs 74.0\%; 3-year CSS, $71.0 \%$ vs. $58.0 \%$; 5 -year CSS, $69.0 \%$ vs. $46.0 \%)$. The 1-, 3-, and 5-year CSS rates in patients with low albumin level were lower than those with high albumin level (1-year CSS, $67.0 \%$ vs $85.0 \%$; 3-year CSS, $51.0 \%$ vs. $72.0 \%$; 5 -year CSS, $51.0 \%$ vs. $67.0 \%$ ).

We combined the SCC-Ag and albumin levels and classified patients into three groups (Group A included patients with low SCC-Ag and high albumin levels; Group B included patients with high SCC-Ag or low albumin levels; Group C included patients with low 


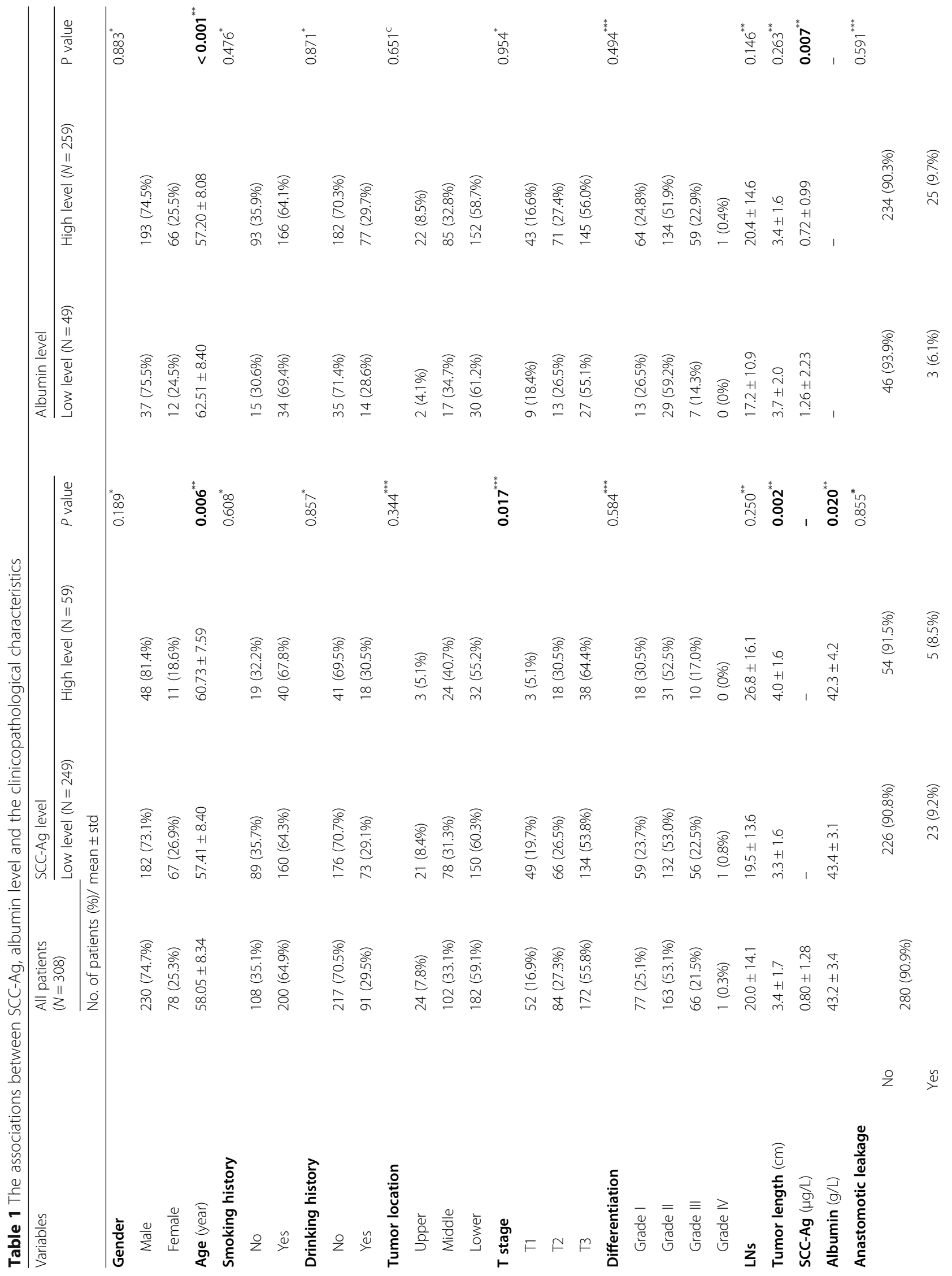




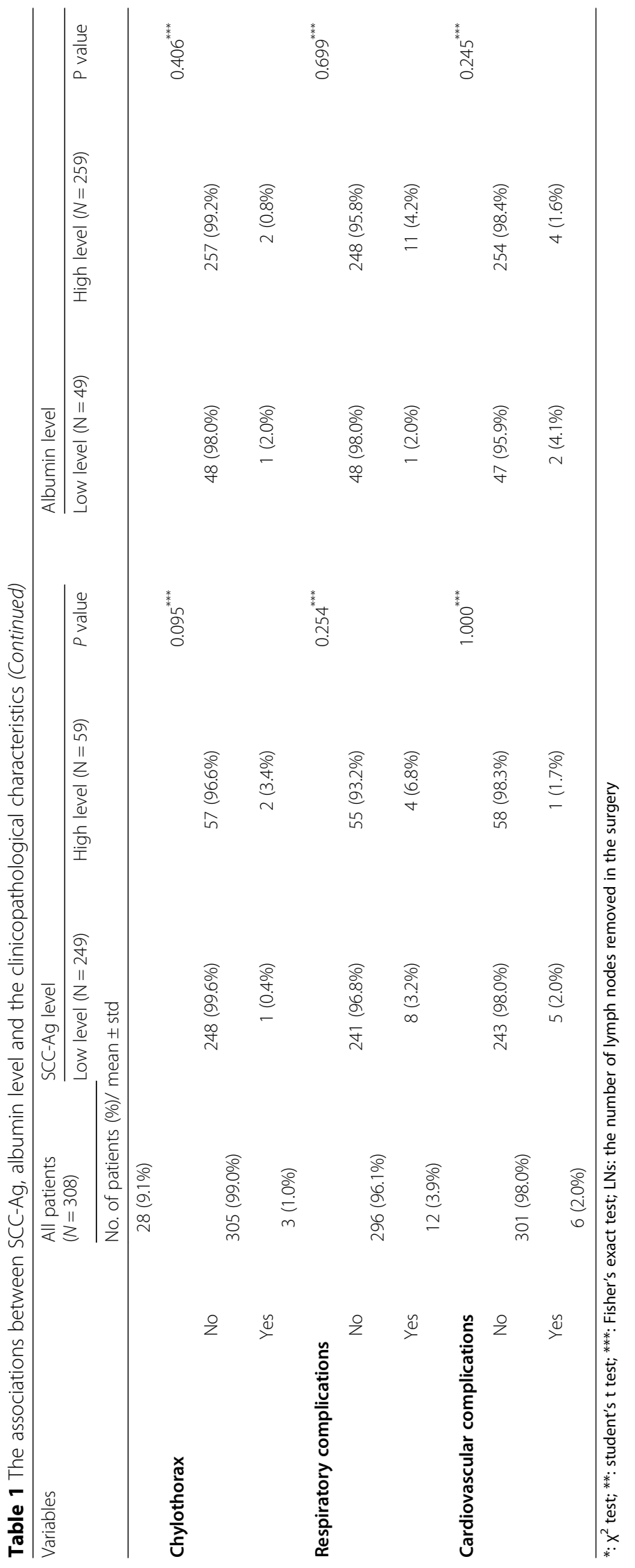




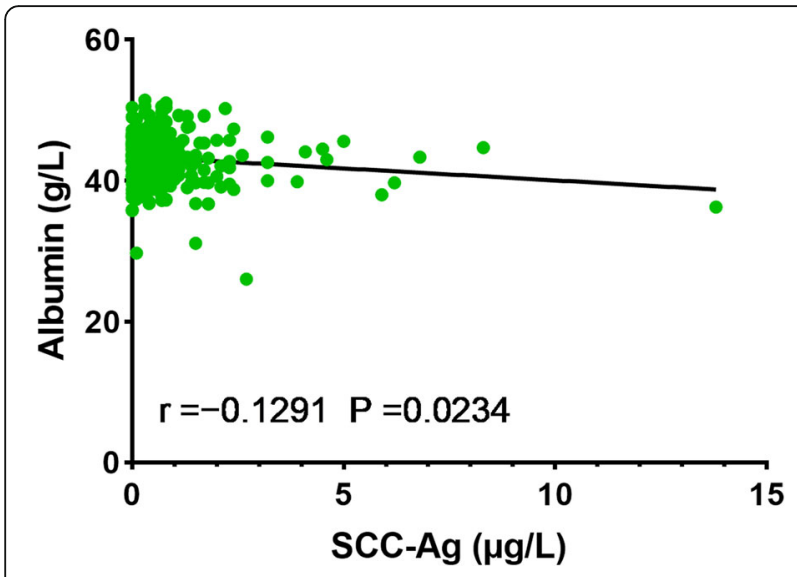

Fig. 2 Correlation between SCC-Ag and albumin levels

albumin and high SCC-Ag levels). We found that Group $C$ had the worst survival than other groups (all $P<0.005$, Fig. 4). The 5-year CSS rate in Groups A, B, and $C$ were $70.0,58.0$ and $25.0 \%$, respectively.

\section{Discussion}

Many factors including smoking history and alcohol consumption were reported to predict ESCC prognosis [22-24]. In this retrospective study, we explored the prognostic role of preoperative SCC-Ag and albumin levels in a large sample of 308 patients with ESCC with stage T1-3N0M0. We analyzed the data of these patients. Eventually, we found that SCC-Ag and albumin levels could be prognostic predictive indicators. In addition, albumin level was likely to be a protective prognostic factor, but SCC-Ag level might be a risk factor (Table 2). This study was the first to combine SCC$\mathrm{Ag}$ and albumin levels to further analyze prognosis of patients with ESCC with stage T1-3N0M0. The results showed that patients with low albumin and high SCCAg levels had the worst 5-year CSS than patients in the two other groups (Fig. 4). Given that the information of preoperative SCC-Ag and albumin levels can be conveniently obtained from medical records, our findings had a certain application value. Based on the survival outcomes observed in this study, patients with a high preoperative SCC-Ag level and low albumin level can be advised to undergo more active treatment, such as adjuvant chemotherapy and radiotherapy, to achieve better CSS.

More than $90 \%$ of esophageal cancers in China are of squamous carcinoma type, and serum SCC-Ag level had been highly recommended and could be a critical biomarker for prognosis. In a previous study in Japan, the cutoff SCC-Ag level was $1.5 \mu \mathrm{g} / \mathrm{L}$, and the positive rate of SCC-Ag in resected ESCC was 25\% [15]. In our study, the cutoff level determined using X-Tile program was $1.0 \mu \mathrm{g} / \mathrm{L}$, and the positive rate was found to be lower, at

Table 2 Univariate and multivariate Cox regression analysis for cancer specific survival in patients ESCC with stage T1-3N0M0 (Cox regression's method is Forward: LR)

\begin{tabular}{|c|c|c|c|c|c|c|}
\hline \multirow[t]{2}{*}{ Characteristics } & \multicolumn{3}{|c|}{ Univariate analysis } & \multicolumn{3}{|c|}{ Multivariate analysis } \\
\hline & $\mathrm{HR}$ & $95 \% \mathrm{Cl}$ & $P$ value & $\mathrm{HR}$ & $95 \% \mathrm{Cl}$ & $P$ value \\
\hline Gender (male vs. female) & 0.722 & $0.456-1.141$ & 0.163 & & & \\
\hline Age (continuous) & 1.020 & $0.997-1.043$ & 0.082 & & & \\
\hline Smoking history (no vs. yes) & 1.608 & $1.059-2.443$ & 0.036 & - & - & 0.283 \\
\hline Drinking history (no vs. yes) & 1.681 & $1.150-2.459$ & 0.007 & 1.878 & $1.275-2.765$ & 0.001 \\
\hline \multicolumn{7}{|l|}{ Primary tumor location } \\
\hline Upper (reference) & 1 & - & - & & & \\
\hline Middle & 0.728 & $0.334-1.585$ & 0.424 & & & \\
\hline Lower & 1.023 & $0.688-1.522$ & 0.910 & & & \\
\hline p T stage (T1 vs. T2 vs. T3) & 1.445 & $1.102-1.894$ & 0.008 & 1.551 & $1.167-2.061$ & 0.002 \\
\hline SCC-Ag (continuous) & 1.227 & $1.105-1.361$ & $<0.001$ & 1.200 & $1.083-1.330$ & 0.001 \\
\hline Albumin (continuous) & 0.939 & $0.889-0.991$ & 0.022 & 0.945 & $0.896-0.997$ & 0.038 \\
\hline LNs (continuous) & 0.984 & $0.969-0.999$ & 0.040 & 0.982 & $0.967-0.997$ & 0.020 \\
\hline Tumor length (continuous) & 1.070 & $0.960-1.194$ & 0.222 & & & \\
\hline Anastomotic leakage (no vs. yes) & 1.078 & $0.579-2.009$ & 0.812 & & & \\
\hline Chylothorax (no vs. yes) & 1.066 & $0.149-7.640$ & 0.949 & & & \\
\hline Respiratory complications (no vs. yes) & 0.880 & $0.324-2.389$ & 0.803 & & & \\
\hline Cardiovascular complications (no vs. yes) & 1.118 & $0.276-4.529$ & 0.876 & & & \\
\hline
\end{tabular}

The factors in the univariate analyses with $P$ value less than 0.05 would be took in account into multivariate analyses. $L N s$ the number of lymph nodes removed in surgery, $\mathrm{HR}$ hazard ratio, $\mathrm{Cl}$ confident interval 
A.

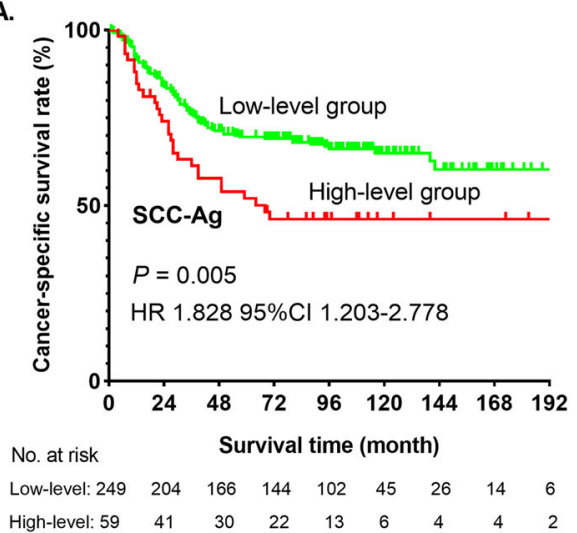

B.

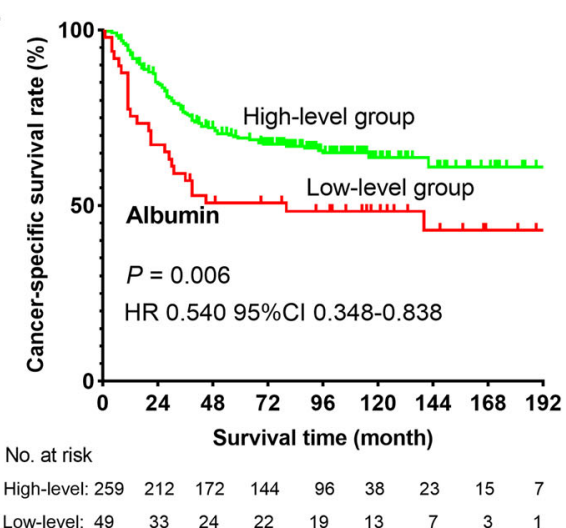

Fig. 3 Cancer-specific survival curve for the whole cohort of patients with ESCC with stage T1-3NOMO according to the preoperative serum SCC$\mathrm{Ag}(\mathbf{a})$ and albumin (b) levels

19.2\%. This difference could be attributed to disparity of TNM stage and our low SCC-Ag cutoff level $(1.0 \mu \mathrm{g} / \mathrm{L})$. The varying surgical indications among hospitals may have also caused sampling bias. In clinical practice, the optimal cutoff SCC-Ag level to determine high-risk patients with ESCC remains controversial. The widely used level of $1.5 \mu \mathrm{g} / \mathrm{L}$ was based on an overall population; however, it is not likely to reflect the risk of prognosis in patients with ESCC. Our study explored a new cutoff
SCC-Ag level $(1.0 \mu \mathrm{g} / \mathrm{L})$, and the two groups that were grouped based on this level showed a strong difference in survival $(P=0.005)$. In this study, we observed that the SCC-Ag level adjusted for tumor staging was an independent prognostic factor for patients with ESCC, similar to the results of Shimada et al. $[15,25]$. The most likely explanation was that the SCC-Ag level is mainly determined by tumor volume and internal potential for malignancy, such as expression of gene Wnt-11 $[11,26]$,

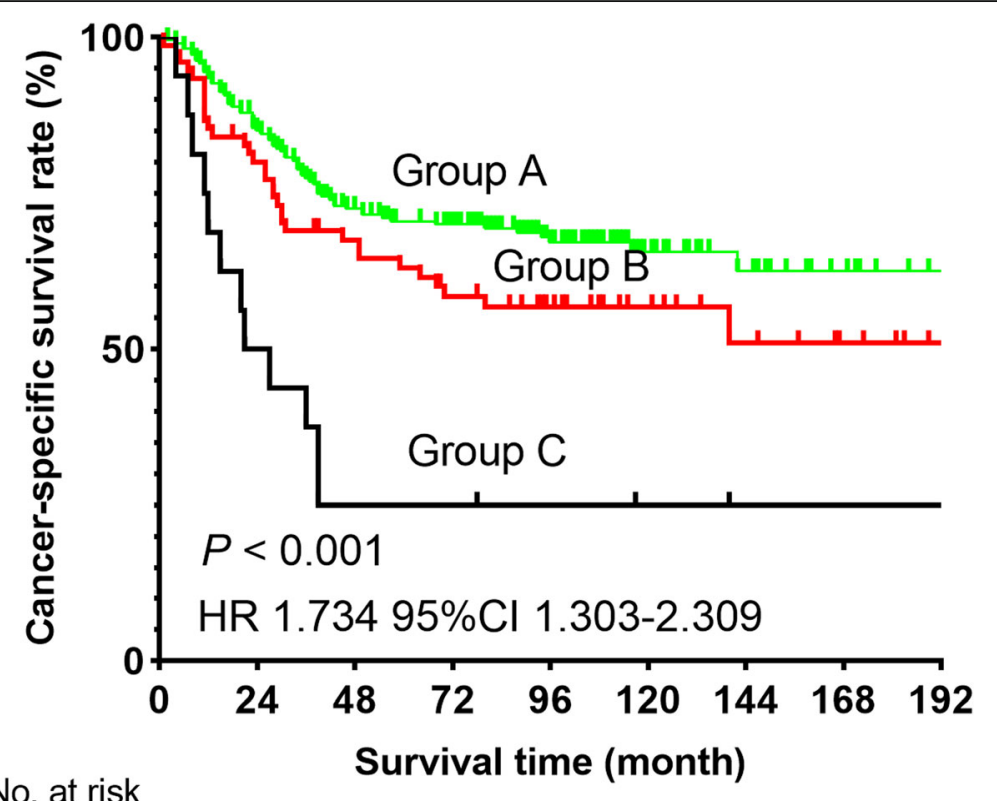

No. at risk

$\begin{array}{lcccccccc}\text { Group A: } 216 & 179 & 146 & 126 & 86 & 34 & 20 & 12 & 6 \\ \text { Group B: } 76 & 58 & 46 & 36 & 26 & 15 & 9 & 5 & 1 \\ \text { Group C: } 16 & 8 & 4 & 4 & 3 & 2 & 1 & 1 & 1\end{array}$

Fig. 4 Cancer-specific survival curve for the whole cohort of patients with ESCC according to the groups (Group A included low SCC-Ag and high albumin levels; Group B included patients with high SCC-Ag or low albumin levels; Group C included patients with low albumin and high SCC-Ag levels) 
which cannot be well described by the TNM staging system. For example, as for T staging of ESCC, we only consider the depth of tumor invasion rather than tumor size or volume. Similarly, in our study, SCC-Ag level was considered as an independent prognostic factor adjusted for pT stage (Table 2).

In addition, in the field of ESCC, a previous study suggested that the Glasgow Prognostic Score (GPS) could be a prognostic factor for disease-free survival [27]. Of note, the GPS system included albumin and C-reactive protein levels, and the observed endpoint of Matsuda's study was different from ours [27]. In another study, Han et al. collected the information of 101 patients with esophageal adenocarcinoma and found that patients with albumin level $\geq 40.0 \mathrm{~g} / \mathrm{L}$ had better overall survival by analyzing their data $(P<0.05)$ [28]. Similarly, we illustrated that patients with albumin level $>39.8 \mathrm{~g} / \mathrm{L}$ had more survival advantage than patients with albumin level $\leq 39.8 \mathrm{~g} / \mathrm{L}$. However, there were some differences between our study and Han's study, such as observed endpoint and pathological types of esophageal cancer. Therefore, it is significant to explore the effect of preoperative albumin level on CSS of patients with ESCC with stage T1-3N0M0.

As a retrospective study, this had certain limitations. First, the patients were unevenly distributed in each $\mathrm{T}$ stage, and this may have affected our results. To the best of our knowledge, ESCC patients with metastasis of LNs have a poor survival outcome. In fact, the status of LNs may reflect the malignancy of ESCC and affect the serum SCC-Ag level. However, patients with LN-positive ESCC were not included in this study. Accordingly, a large sample size is needed for further analysis. In addition, we are likely to recruit patients with metastasis of LNs to further explore the association between the status of LNs and SCC-Ag level. Second, our follow-up data lacked the regular surveillance of postoperative SCC-Ag and albumin levels, restricting evaluation of the role of postoperative SCC and albumin levels on long-term follow-up monitoring of patients with ESCC. Postoperative SCC-Ag level, albumin level, and detailed follow-up, including tumor recurrence and metastasis status, are also vital in analyzing the prognostic roles in patients with ESCC with stage T13NOM0. Third, the cutoff SCC-Ag level $(1.0 \mu \mathrm{g} / \mathrm{L})$ and albumin level $(39.8 \mathrm{~g} / \mathrm{L})$ determined by X-Tile software are likely to be affected by "human factors." We suggested that SCC-Ag and albumin levels might be independent prognostic factors by analyzing continuous values (Table 2) and then stratifying the patients using the abovementioned cutoff levels. However, there are still some differences in cutoff levels between our study and other studies. Therefore, appropriate statistical methods and adequate sample size are needed to further determine the optimal cutoff levels.

\section{Conclusions}

The preoperative SCC-Ag and albumin levels, apart from the TNM staging system, were independent prognostic factors for ESCC in stage T1-3NOM0. In addition, patients with low albumin and high SCC-Ag levels had worst 5-year CSS than other patients. However, further study is needed to explore the impact of SCC-Ag and albumin levels on the prognosis of patients with ESCC with stage T1-3N0M0.

\section{Abbreviations \\ SCC-Ag: squamous cell carcinoma antigen; CT: computed tomography; CSS: cancer-specific survival; ESCC: esophageal squamous cell cancer; HR: Hazard Ratio; Cl: Confidential Interval; SYSUCC: Sun Yat-sen University Cancer Center; AJCC: American Joint Committee on Cancer; LNs: lymph nodes; std.: standard deviation}

\section{Acknowledgements}

Thank all patients and staff from SYSUCC for their contribution in providing surveillance data and support. The authors appreciated Enago (www.enago.cn) and Editage (https://app.editage.com) for the English language review.

\section{Authors' contributions}

WLL designed the research and wrote the article; LX processed data; HW recorded the data of patients; LP, LH, and ZLJ reviewed and edited the article; MGW analyzed the data and reviewed the article. The author(s) read and approved the final manuscript.

\section{Funding}

This work was supported by the Science and Technology Planning Project of Guangdong Province, China (No. 2012B031800463) and the Science and Technology Planning Project of Guangdong Province, China (No. 2013B022000040).

\section{Availability of data and materials}

Please contact author for data requests. The data of this study have loaded in the Research Data Deposit (No. RDDA2020001402, www. researchdata.org.cn).

\section{Ethics approval and consent to participate}

The study protocol was approved by the Ethics Committee of Sun Yat-sen University Cancer Center (Approval No: YB2016-070), and consent was waived.

\section{Consent for publication}

All authors agree with publication in this journal.

\section{Competing interests}

The authors declare that they have no competing interests.

Received: 27 January 2020 Accepted: 18 May 2020

Published online: 26 May 2020

\section{References}

1. Bray F, Ferlay J, Soerjomataram I, Siegel RL, Torre LA, Jemal A. Global cancer statistics 2018: Globocan estimates of incidence and mortality worldwide for 36 cancers in 185 countries. CA Cancer J Clin. 2018. PMID;68(6):394-424. https://doi.org/10.3322/caac.21492.

2. Feng RM, Zong YN, Cao SM, Xu RH. Current cancer situation in china: Good or bad news from the 2018 global cancer statistics? Cancer Commun (Lond). 2019. PMID: PMC6487510;39(1):22. https://doi.org/10.1186/s40880-019-0368-6.

3. Ferlay J, Shin HR, Bray F, Forman D, Mathers C, Parkin DM. Estimates of worldwide burden of cancer in 2008: Globocan 2008. Int J Cancer. 2010. PMID;127(12):2893-917. https://doi.org/10.1002/ijc.25516.

4. Liang $H$, Fan JH, Qiao YL. Epidemiology, etiology, and prevention of esophageal squamous cell carcinoma in china. Cancer Biol Med. 2017. PMID: PMC5365188;14(1):33-41. https://doi.org/10.20892/j.issn.2095-3941.2016.0093. 
5. Huang J, Xu B, Liu Y, Huang J, Lu P, Ba Y, Wu L, Bai Y, Zhang S, Feng J, Cheng Y, Li J, Wen L, Yuan X, Ma C, Hu C, Fan Q, Wang X. Irinotecan plus s1 versus s-1 in patients with previously treated recurrent or metastatic esophageal cancer (eswn 01): A prospective randomized, multicenter, openlabeled phase 3 trial. Cancer Commun (Lond). 2019. PMID: PMC6444575; 39(1):16. https://doi.org/10.1186/s40880-019-0359-7.

6. Cao X, Zhang L, Feng GR, Yang J, Wang RY, Li J, Zheng XM, Han YJ. Preoperative Cyfra21-1 and SCC-Ag serum titers predict survival in patients with stage II esophageal squamous cell carcinoma. J Transl Med. 2012. https://doi.org/10.1186/1479-5876-10-197.

7. Huang SF, Wei FC, Liao CT, Wang HM, Lin CY, Lo S, Huang JJ, Chen IH, Kang $\mathrm{CJ}$, Chien HT, Chen HH. Risk stratification in oral cavity squamous cell carcinoma by preoperative crp and scc antigen levels. Ann Surg Oncol. 2012. PMID;19(12):3856-64. https://doi.org/10.1245/s10434-012-2392-5.

8. Xu D, Wang D, Wang S, Tian Y, Long Z, Ren X. Correlation between squamous cell carcinoma antigen level and the clinicopathological features of early-stage cervical squamous cell carcinoma and the predictive value of squamous cell carcinoma antigen combined with computed tomography scan for lymph node metastasis. Int J Gynecol Cancer. 2017. PMID;27(9): 1935-42. https://doi.org/10.1097//GC.0000000000001112.

9. Li ZS, Yao K, Li YH, Chen JP, Deng CZ, Zhao Q, Chen P, Wang B, Mi QW, Liu ZW, Qin ZK, Han H, Zhou FJ. Clinical significance of preoperative c-reactive protein and squamous cell carcinoma antigen levels in patients with penile squamous cell carcinoma. BJU Int. 2016. PMID;118(2):272-8. https://doi.org/ 10.1111/bju.13379.

10. Shao T, Huang J, Zheng Z, Wu Q, Liu T, Lv X. Scca, tsgf, and the long noncoding rna ac007271.3 are effective biomarkers for diagnosing oral squamous cell carcinoma. Cell Physiol Biochem. 2018. PMID;47(1):26-38. https://doi.org/10.1159/000489741.

11. Jantharapattana K, Kotamnivates T, Hirunpat S, Jarumanokul R. Correlation between serum squamous cell carcinoma antigen level and tumor volume in head and neck cancer. ORL J Otorhinolaryngol Relat Spec. 2018. PMID; 80(5-6):284-9. https://doi.org/10.1159/000491494

12. Deng Z, Hasegawa M, Yamashita Y, Matayoshi S, Kiyuna A, Agena S, Uehara T, Maeda H, Suzuki M. Prognostic value of human papillomavirus and squamous cell carcinoma antigen in head and neck squamous cell carcinoma. Cancer Sci. 2012. PMID;103(12):2127-34. https://doi.org/10.1111/cas.12009.

13. Ayhan A, Gunakan E, Alyazici I, Haberal N, Altundag O, Dursun P. The preoperative albumin level is an independent prognostic factor for optimally debulked epithelial ovarian cancer. Arch Gynecol Obstet. 2017 PMID;296(5):989-95. https://doi.org/10.1007/s00404-017-4511-9.

14. Seebacher V, Grimm C, Reinthaller A, Heinze G, Tempfer C, Hefler L, Polterauer $\mathrm{S}$. The value of serum albumin as a novel independent marker for prognosis in patients with endometrial cancer. Eur J Obstet Gynecol Reprod Biol. 2013. PMID;171(1):101-6. https://doi.org/10.1016/j.ejogrb.2013.07.044.

15. Shimada H, Nabeya Y, Okazumi S, Matsubara H, Shiratori T, Gunji Y, Kobayashi $\mathrm{S}$, Hayashi H, Ochiai T. Prediction of survival with squamous cell carcinoma antigen in patients with resectable esophageal squamous cell carcinoma. Surgery. 2003. PMID;133(5):486-94. https://doi.org/10.1067/msy.2003.139.

16. Hong Yang HL, Yuping Chen: Neoadjuvant chemoradiotherapy followed by surgeryversus surgery alone for locally advanced squamous cell carcinoma of the esophagus (neocrtec5010): a phase iii multicenter, randomized, openlabel clinical trial. J Clin Oncol (36): 2796-2803, 2018. PMID, doi: https://doi. org/10.1200/JCO10.1200/JCO.2018.

17. Hsu PK, Chen HS, Liu CC, Wu SC. Application of the eighth ajcc tnm staging system in patients with esophageal squamous cell carcinoma. Ann Thorac Surg. 2018. PMID;105(5):1516-22. https://doi.org/10.1016/j. athoracsur.2017.12.032.

18. Zhang D, Zheng Y, Wang Z, Huang Q, Cao X, Wang F and Liu S: Comparison of the 7th and proposed 8th editions of the ajcc/uicc tnm staging system for esophageal squamous cell carcinoma underwent radical surgery. Eur J Surg Oncol 43(10): 1949-1955, 2017. PMID, doi: https://doi.org/10.1016/j.ejso.2017.06.005.

19. Li Y, Liang L, Dai W, Cai G, Xu Y, Li X, Li Q, Cai S. Prognostic impact of programed cell death-1 (pd-1) and pd-ligand 1 (pd-11) expression in cancer cells and tumor infiltrating lymphocytes in colorectal cancer. Mol Cancer. 2016. PMID: PMC4995750;15(1):55. https://doi.org/10.1186/s12943-016-0539-x.

20. Qureshi YA, Sarker SJ, Walker RC, Hughes SF. Proximal resection margin in ivor-Lewis oesophagectomy for cancer. Ann Surg Oncol. 2017. PMID;24(2): 569-77. https://doi.org/10.1245/s10434-016-5510-y.
21. Camp RL, Dolled-Filhart M, Rimm DL. X-tile: a new bio-informatics tool for biomarker assessment and outcome-based cut-point optimization. Clin Cancer Res. 2004;10:7252-9 Available at http://clincancerres.aacrjournals.org/ content/10/21/7252.

22. Wu IC, Wu CC, Lu CY, Hsu WH, Wu MC, Lee JY, Chou SH, Lee JM, Chou YP, Wu DC, Wu MT. Substance use (alcohol, areca nut and cigarette) is associated with poor prognosis of esophageal squamous cell carcinoma. PLoS One. 2013. PMID: PMC3567035;8(2):e55834. https://doi.org/10.1371/ journal.pone.0055834.

23. Lin $Y$, Su $X$, Su H, Lin P, Long H, Zhang L, Fu J, Rong T, Tan Z, Meng Y, Ma G. Prediagnostic smoking and postoperative survival in lymph nodenegative esophagus squamous cell carcinoma patients. Cancer Sci. 2012. PMID;103(11):1985-8. https://doi.org/10.1111/cas.12000.

24. Yuequan J, Shifeng C, Bing Z. Prognostic factors and family history for survival of esophageal squamous cell carcinoma patients after surgery. Ann Thorac Surg. 2010. PMID;90(3):908-13. https://doi.org/10.1016/j. athoracsur.2010.05.060.

25. Salvatici M, Achilarre MT, Sandri MT, Boveri S, Vanna Z, Landoni F. Squamous cell carcinoma antigen (scc-ag) during follow-up of cervical cancer patients: role in the early diagnosis of recurrence. Gynecol Oncol. 2016. PMID;142(1):115-9. https://doi.org/10.1016/j.ygyno.2016.04.029.

26. Wei H, Wang N, Zhang Y, Wang S, Pang X, Zhang J, Luo Q, Su Y, Zhang S. Clinical significance of wnt-11 and squamous cell carcinoma antigen expression in cervical cancer. Med Oncol. 2014. PMID;31(5):933. https://doi. org/10.1007/s12032-014-0933-4.

27. Matsuda S, Takeuchi H, Kawakubo H, Fukuda K, Nakamura R, Takahashi T, Wada N, Saikawa Y, Omori T, Kitagawa Y. Cumulative prognostic scores based on plasma fibrinogen and serum albumin levels in esophageal cancer patients treated with transthoracic esophagectomy: comparison with the Glasgow prognostic score. Ann Surg Oncol. 2015. PMID;22(1):302-10. https://doi.org/10.1245/s10434-014-3857-5.

28. Han WX, Chen ZM, Wei ZJ, Xu AM. Preoperative pre-albumin predicts prognosis of patients after gastrectomy for adenocarcinoma of esophagogastric junction. World J Surg Oncol. 2016. PMID: PMC5094092; 14(1):279. https://doi.org/10.1186/s12957-016-1035-x.

\section{Publisher's Note}

Springer Nature remains neutral with regard to jurisdictional claims in published maps and institutional affiliations.

Ready to submit your research? Choose BMC and benefit from:

- fast, convenient online submission

- thorough peer review by experienced researchers in your field

- rapid publication on acceptance

- support for research data, including large and complex data types

- gold Open Access which fosters wider collaboration and increased citations

- maximum visibility for your research: over $100 \mathrm{M}$ website views per year

At $\mathrm{BMC}$, research is always in progress.

Learn more biomedcentral.com/submissions 